OnLine Journal of Biological Sciences 12 (2): 72-79, 2012

ISSN 1608-4217

(C) 2012 D.S. Buchan et al., This open access article is distributed under a Creative Commons Attribution

(CC-BY) 3.0 license

\title{
Prevalence of Cardiovascular Disease Risk Factors among Scottish Youth: A Pilot Investigation
}

\author{
${ }^{1}$ D.S. Buchan, ${ }^{1}$ J.D. Young, ${ }^{1}$ L. Kilgore, \\ ${ }^{2}$ S.M. Cooper, ${ }^{3}$ R.M. Malina and ${ }^{1}$ J.S. Baker \\ ${ }^{1}$ Institute for Clinical Exercise and Health Science, School of Science, \\ University of the West of Scotland, Hamilton, ML3 0JB, Scotland, UK \\ ${ }^{2}$ Cardiff School of Sport, Cardiff Metropolitan University, \\ Cyncoed Campus, Cyncoed Road, Cardiff, CF23 6XD, Wales, UK \\ ${ }^{3}$ Department of Kinesiology and Health Education, The College of Education, \\ University of Texas at Austin, 1 University Station-D3700, Austin, TX 78712-0360, USA
}

\begin{abstract}
Problem statement: Approximately $70 \%$ of the total ethnic minority population of Scotland is of South Asian ancestry, although relatively little is known about their cardiovascular risk profile. Determining the risk profiles of Scottish youth of South Asian ancestry may inform the creation of interventions to reduce risk and improve the quality of life in this population. Approach: The purpose of this pilot investigation was to examine the Cardiovascular Disease (CVD) risk profiles of Scottish youth of South Asian ancestry. A sample of 48 South Asian adolescents (26 females, 22 males, $16 \pm 2$ years of age) resident in the city of Glasgow participated in this study. Stature, mass, waist circumference, physical activity, blood pressure, diet and 10 metabolic markers of CVD risk were recorded. Results: Boys had a significantly $(\mathrm{p} \leq 0.01)$ greater body mass, stature and were more physically active than girls. The boys also had significantly $(\mathrm{p} \leq 0$. 05) higher fasting levels of glucose, LDL and C-Reactive Protein (CRP) and recorded lower levels of HDL than girls. High fat diets, low physical activity, elevated CRP, glucose and insulin levels and low HDL levels were the risk factors most often identified as being as non-desirable. About $88 \%$ of the cohort had between 2 and 6 CVD risk factors while $40 \%$ of boys and $20 \%$ of girls presented with 5 or more risk factors. Conclusion/Recommendations: Results suggest that preventive measures, including increased physical activity and dietary management may be warranted for the youth of South Asian ancestry.
\end{abstract}

Keywords: Cardiovascular Disease (CVD), Systolic Blood Pressure (SBP), Diastolic Blood Pressure (DBP), Physical Activity Questionnaire for Adolescents (PAQ-A)

\section{INTRODUCTION}

Cardiovascular Disease (CVD) accounted for over 191,000 deaths in the United Kingdom (UK) in 2008 and was the main cause of mortality in Scotland $(17,000)$, accounting for nearly a third of all deaths (BHF, 2010). The incidence of CVD results from a complex interaction of several risk factors all of which predispose individuals to its incidence over their lifetime. Obesity at any age is a risk factor for CVD which is associated with other co-morbidities such as type 2 diabetes, hypertension, asthma, depression, certain cancers and sleep apnoea (Steinberger et al., 2009). Although risk elevation with obesity is consistent across age groups, childhood obesity rates and its presence as a CVD risk factor apparently varies by ethnic origin (Whincup et al., 2005; Yajnik, 2002).
Several studies have shown that at low BMI levels pre-adolescent English youth of South Asian ancestry had a poorer CVD risk profile than youth of European (White) ancestry (Whincup et al., 2002; 2010). A similar study of adolescents, also showed South Asian youth had a greater predisposition to Type 2 diabetes that their white peers when adiposity was statistically controlled (Whincup et al., 2005). Genetic factors have been implicated in the elevated incidence of CVD risk in South Asian youth, as have environmental settings and dietary habits (Giskes et al., 2011). For example, there is a strong association between an individual's food environment and weight status (Giskes et al., 2011). The Scottish diet is notoriously poor in comparison with other nations in the UK. The Scottish diet consists of the highest intake of saturated fat and

Corresponding Author: Buchan, D.S., Institute for Clinical Exercise and Health Science, School of Science, University of the West of Scotland, Hamilton, ML3 0JB, Scotland, UK 
lowest intake of fruit and vegetables compared to diets in Wales, Northern Ireland and England (DEFRA, 2004). The prevalence of CVD risk is positively associated with length of residence among South Asian migrants and it has been suggested that the offspring of migrant parents is more likely to engage with the local culture, making them more susceptible to an increased prevalence of CVD risk (Harding et al., 2008).

Approximately $70 \%$ of the total ethnic minority population of Scotland is of South Asian ancestry, although relatively little is known about their CVD risk profile (SG, 2004). The purpose of this pilot study was to investigate the prevalence of novel and traditional CVD risk factors in a cohort of Scottish youth of South Asian ancestry. The observations may inform future large scale investigations which could provide important information regarding the prevalence of CVD risk in ethnic populations residing in Scotland. Further, this information may inform the creation of interventions to reduce risk and improve the quality of life in this population.

\section{MATERIALS AND METHODS}

A sample of 48 Scottish youth of South Asian ancestry, 26 females and 22 males (16 \pm 2 years of age) from the city of Glasgow participated in the study. All participants were born and resided in Scotland. Selfreported ethnicity indicated 60\% Pakistani and 40\% Indian descent. Participants were recruited with the aid of the data base of the Scottish Ethnic Minority Sports Association (SEMSA). Key community leaders were approached for advice before visits to community and religious centers were undertaken for the purpose of recruiting subjects. All participants were assured full anonymity and informed of their right to withdraw from the study at any point. Information sheets and participant and parent/guardian consent forms were distributed. Only those who returned completed consent were permitted to participate. Participants were instructed to maintain their daily routines and not to change dietary and lifestyle habits prior to data collection. Ethical approval was granted by the University of the West of Scotland ethics committee.

Anthropometry: Stature, (barefoot), was measured to the nearest $1 \mathrm{~mm}$ (Seca Stadiometer, Seca Ltd, Birmingham, UK). Mass in light indoor clothing, without shoes, was recorded to the nearest $0.1 \mathrm{~kg}$ using a calibrated electronic weighing scale (Seca 880, Digital Scales, Seca Ltd, Birmingham, UK). Body mass

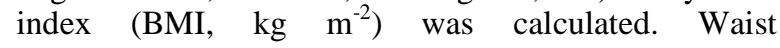
Circumference (WC) was measured at the midpoint between the lower ribs and iliac crest following standard procedures (Ledoux et al., 1997). All measures were recorded by specialists trained in anthropometric measurement. Sexual maturity status was estimated based on stage of Pubic Hair (PH) development using the criteria of (Tanner, 1962).

Blood pressure: Systolic Blood Pressure (SBP) and Diastolic Blood Pressure (DBP) were recorded with an automated monitor (Omron M10-IT Blood Pressure Monitor HEM-7080IT-E, Omron Healthcare UK Ltd, Milton Keynes, UK) after each participant sat quietly for a period of $10 \mathrm{~min}$ as previously documented (Andersen et al., 2003).

Diet and physical activity: Daily food intake was estimated with a validated, self-reported seven-day food diary (McCance and Widdowson, 2002) and a food frequency questionnaire. Participants were instructed to complete the food diary and record everything that they ate and drank over a specified seven-day period. Participants were encouraged to continue their normal eating and drinking behaviors during the seven day recording period. Returned food diaries and questionnaires were inspected and responses clarified, if necessary. The collated data were analyzed with the nutritional analysis software (Nutri Check, Health Options Ltd, Cirencester, Gloucester, UK). Daily kilocalories $(\mathrm{kcal} / \mathrm{d})$, percentage of total fat and saturated fat were then calculated.

Participants also completed a validated Physical Activity Questionnaire for Adolescents (PAQ-A) (Kowalski et al., 1997), which required the recall and documentation of PA behavior over the previous 7 days. This validated questionnaire has been used in previous research by American (Janz et al., 2008) and British (Buchan et al., 2011) youth. It provides a score for each individual ranging from $0-5$, with 0 reflecting no physical activity and 5 being very physically active. The PAQ-A is particularly useful as an indicator of general activity patterns that can discriminate between active and inactive individuals rather than trying to estimate the intensity and duration of activities. From previous experience, completion of the questionnaire required no longer than $30 \mathrm{~min}$ to complete and was completed during the scheduled consultation time with subjects. Completed questionnaires were inspected and if necessary, responses were clarified with the participant.

Cardiometabolic indicators: Blood samples were collected between 9:00 and 11:00 am after an overnight fast. Prior to sampling, participants were instructed to sit quietly for a period of at least $30 \mathrm{~min}$ to control for plasma volume shifts (Pronk, 1993). A team of qualified phlebotomists, experienced in pediatric sampling techniques collected the blood samples. Blood samples were obtained from an antecubital vein and were stored in BD Vacutainer plasma tubes (Becton, Dickinson and Company, Franklin Lakes, USA). Plasma was isolated by centrifugation at 3,500 RPM for 
$10 \mathrm{~min}$ and frozen at $-80^{\circ} \mathrm{C}$ within $2 \mathrm{~h}$ of collection. Analyses were subsequently completed within five months of collection. Total Cholesterol (TC), insulin, High-Density Lipoprotein Cholesterol (HDL), LowDensity Lipoprotein cholesterol (LDL), high-sensitivity C-reactive Protein (CRP), glucose, interleukin-6 (IL-6), adiponectin, triglycerides and Plasminogen Activator Inhibitor-1 (PAI-1) were measured. All analyses were performed using standard procedures. Total cholesterol and triglycerides were measured using enzymatic methods (TR210 and CH200Randox, Co. Antrim, UK) and a Camspec M107 spectrophotometer (Camspec, Leeds, UK). Concentration of HDL was determined after precipitation of very low density and low-density lipoproteins by the addition of phosphotungstic acid in the presence of magnesium ions. The Friedewald formula (Friedewald et al., 1972) was used to calculate LDL concentration. Glucose was measured using the glucose oxidase method (GL364, Randox, Co. Antrim, UK) and analyzed using a Camspec M107 spectrophotometer (Camspec, Leeds, UK). Plasma insulin was measured with commercially available immunoassay kits (ALPCO, Salem, NH, USA) and analyzed with a Camspec M107 spectrophotometer (Camspec, Leeds, UK). Concentrations of IL-6, CRP, adiponectin and PAI-1 were measured with specific enzyme linked immune-Sorbent assay ELISA kits ( $R$ and D Systems, Abingdon, UK) and a MRX microplate reader (Dynatech Laboratories, Cambridge, MA, USA). All samples were measured in duplicate.

Classification of youth at risk: Established criteria were used to classify each participant with each indicator of CVD risk. This method was used, given the lack of ethnic specific at risk thresholds for all but one risk factor measured. Weight status was classified on the basis of the BMI as obese, overweight, healthy weight or thin using internationally recognized age- and gender-specific cutoffs (Cole et al., 2007). For WC, the ethnic specific circumferences used to identify risk levels were those proposed by the International Diabetes Federation which were; $\geq 90 \mathrm{~cm}$ for men and $\geq 80 \mathrm{~cm}$ for women. The dietary lipid contents considered to increase CVD risk were $>30 \%$ total fat and $>10 \%$ saturated fat in the diet (WHO, 2003).

Age- and gender-specific cutoff points proposed by the International Diabetes Federation for individuals $<16$ years (Zimmet et al., 2007) were used for triglycerides, HDL, SBP, DBP and glucose. The following cutoff points were used to identify participants at risk: elevated triglycerides $(\geq 1.7 \mathrm{mmol}$ $\left.\mathrm{L}^{-1}\right)$, low HDL $\left(<1.03 \mathrm{mmol} \mathrm{L}^{-1}\right)$, high BP (Systolic, $\geq 130$ or diastolic $\geq 85 \mathrm{~mm} \mathrm{Hg}$ ) and elevated blood glucose ( $\geq 5.6 \mathrm{mmol} \mathrm{\textrm {L } ^ { - 1 }}$ ) (Zimmet et al., 2007). International Diabetes Foundation recommendations for adults were used for youth $\geq 16$ years. The only criteria for low HDL differed: for older youth, <1.29 and 1.03 mmol $\mathrm{L}^{-1}$ for females and for males, respectively. At risk thresholds for total cholesterol and LDL adopted for the analysis were $\geq 4.73 \mathrm{mmol} \mathrm{L}^{-1}$ (total cholesterol) and $\geq 3.18 \mathrm{mmol} \mathrm{L}^{-1}$ (LDL) for boys and $\geq 5.12 \mathrm{mmol}$ $\mathrm{L}^{-1}$ (total cholesterol) and $\geq 3$. $34 \mathrm{mmol} / \mathrm{L}$ (LDL) for girls (Tamir et al., 1981). Levels at $<1.0 \mathrm{mg} \mathrm{L}^{-1}$ and $\geq 1.0 \mathrm{mg} \mathrm{L}^{-1}$ indicated low risk and at risk status, respectively, for CRP (Pearson et al., 2003). At risk fasting insulin levels were set at $>15 \mu \mathrm{mL}^{-1}$ and was used to identify participants with hyperinsulinemic levels that may suggest insulin resistance (Ten and Maclaren, 2004). Thresholds of $<1.0 \mathrm{mg} \mathrm{L}^{-1}$ and $\geq 1.0$ $\mathrm{mg} \mathrm{\textrm {L } ^ { - 1 }}$ indicated low risk and at risk status, respectively, for CRP (Pearson et al., 2003). Consistent cut-off values have yet to be proposed for PAI-1, IL-6 and adiponectin in youth populations; hence, the prevalence of these markers was not included when identifying at risk participants.

Data analysis: The data were analysed using Minitab 15.0 (Minitab Inc., Philadelphia, PA.). In addition to the calculation of descriptive statistics, independent ttests were performed on all measured and derived variables to compare the means between two groups (male and female). The level of significance was set at $\mathrm{p} \leq 0.05$ throughout.

Levene's test was used to assess the assumption of homogeneity of variance and the Anderson Darling test was used to assess the assumption that the residuals were normally distributed. For variables where the assumptions of normality and /or homogeneity of variance were invalid, the non-parametric MannWhitney test was used. Bonferroni-adjusted t-tests for two independent means were used for significant Fratios while for significant $\mathrm{H}$-values, a Bonferroniadjusted Mann-Whitney $U$ test was applied. The 95\% Confidence Intervals (CI) for the differences between two population means were calculated for all statistically significant post-his findings. Post house and where indicated by statistical significance of t-ratios, Effect Size Statistics (ES) were calculated. Interpretation of ES was based on Cohen's criteria: small $(0.2>d<0.5)$, MOD $(0.5<d<0.8)$ and large $(d>0.8)$ (Cohen, 1988). ES permits an estimate of the power (\%) of each significant t-ratio.

\section{RESULTS}

Descriptive statistics for all variables are summarized in Table 1 and 2. Stages of $\mathrm{PH}$ were distributed as follows: boys-PH3 (2), PH5 (20); girls PH4 (3), PH5 (23). With few exceptions, the sample was post-pubertal. Stature, body mass, physical activity, fasting glucose, HDL, LDL and CRP differed significantly by sex $(\mathrm{p}<0.05) \quad($ Table 1 and 2$)$. 
OnLine J. Biol. Sci., 12 (2): 72-79, 2012

Table 1: Descriptive statistics (mean $\pm \mathrm{SD}$ ) for age, anthropometry, blood pressure, anthropometry, physical activity, blood pressures and dietary variables

\begin{tabular}{|c|c|c|c|c|c|c|c|}
\hline $\begin{array}{l}\text { Variables } \\
\text { (units) }\end{array}$ & $\begin{array}{l}\text { Total } \\
(\mathrm{n}=48)\end{array}$ & $\begin{array}{l}\text { Boys } \\
(\mathrm{n}=22)\end{array}$ & $\begin{array}{l}\text { Girls } \\
(\mathrm{n}=26)\end{array}$ & $\begin{array}{l}\text { Estimated } \\
\text { difference } \\
\text { between girls } \\
\text { and boys }\end{array}$ & $\begin{array}{l}(95 \% \mathrm{CI}) \\
\text { differences } \\
\text { between } \\
\text { genders }\end{array}$ & $\begin{array}{l}\text { Effect size } \\
(\text { Power }(\%))\end{array}$ & p-value \\
\hline Age (yr) & $16.4 \pm 1.4$ & $16.6 \pm 1.47$ & $16.2 \pm 1.4$ & & & & NS \\
\hline Stature $(\mathrm{cm})$ & $166.1 \pm 8.4$ & $172.6 \pm 6.52$ & $160.7 \pm 5.4$ & -11.91 & $(-15.38,-8.44)$ & $2.00(100)$ & $<0.001$ \\
\hline Body mass (kg) & $59.7 \pm 12.0$ & $66.8 \pm 11.7$ & $53.7 \pm 8.7$ & -13.13 & $(-19.05,-7.20)$ & $1.29,(99.2)$ & $<0.001$ \\
\hline $\operatorname{BMI}\left(\mathrm{kg} \mathrm{m}^{-2}\right)$ & $21.6 \pm 3.7$ & $22.5 \pm 4.2$ & $20.8 \pm 3.1$ & & & & NS \\
\hline $\begin{array}{l}\text { Waist circumference } \\
(\mathrm{cm})\end{array}$ & $70.5 \pm 17.0$ & $73.0 \pm 21.9$ & (20) & $68.6 \pm 12.2$ & & & NS \\
\hline $\begin{array}{l}\text { Physical activity } \\
\text { (PAQ-A) }\end{array}$ & $2.2 \pm 0.7$ & $2.5 \pm 0.6$ & $1.9 \pm 0.6$ & -0.604 & $(-0.948,-0.261)$ & $1.02(93.5)$ & 0.001 \\
\hline $\mathrm{SBP}(\mathrm{mmHg})$ & $124.6 \pm 13.5(47)$ & $128.6 \pm 16.6$ & $121.1 \pm 9.1(25)$ & & & & NS \\
\hline $\mathrm{DBP}(\mathrm{mmHg})$ & $75.2 \pm 9.5(47)$ & $74.5 \pm 10.4$ & $75.7 \pm 8.7(25)$ & & & & NS \\
\hline Total fat $(\%)$ & $34.0 \pm 5.20$ & $34.8 \pm 5.5$ & $33.2 \pm 4.9$ & & & & NS \\
\hline Saturated fat (\%) & $12.6 \pm 3.0$ & $13.2 \pm 3.5$ & $12.1 \pm 2.7$ & & & & NS \\
\hline kCal d-1 & $1415.1 \pm 366.8$ & $1491.5 \pm 400.6$ & $1350.5 \pm 337.7$ & & & & NS \\
\hline
\end{tabular}

$\underline{\text { Table 2: Descriptive statistics (mean } \pm \mathrm{SD} \text { ) for metabolic cardiovascular disease risk factors in youth by sex }}$

\begin{tabular}{|c|c|c|c|c|c|c|c|}
\hline $\begin{array}{l}\text { Variables } \\
\text { (units) }\end{array}$ & $\begin{array}{l}\text { Boys } \\
(n=22)\end{array}$ & $\begin{array}{l}\text { Girls } \\
(\mathrm{n}=26)\end{array}$ & $\begin{array}{l}\text { Total } \\
(\mathrm{n}=48)\end{array}$ & $\begin{array}{l}\text { Estimated } \\
\text { Difference } \\
\text { between girls } \\
\text { and boys }\end{array}$ & $(95 \% \mathrm{CI})$ & $\begin{array}{l}\text { Effect size } \\
\text { (Power (\%) }\end{array}$ & $\mathrm{p}$-Value \\
\hline Insulin $\left(\mathrm{IU} \mathrm{ml}{ }^{-1}\right)$ & $7.67 \pm 5.42(17)$ & $10.83 \pm 11.00(22)$ & $9.45 \pm 9.04(39)$ & & & & NS \\
\hline Glucose $\left(\mathrm{mMol} \mathrm{L}^{-1}\right)$ & $5.30 \pm 1.30(21)$ & $4.59 \pm 0.71$ & $4.91 \pm 1.06(47)$ & -0.717 & $(-1.316,-0.119)$ & $0.71(65.1)$ & 0.020 \\
\hline Triglyceride $\left(\mathrm{mMol} \mathrm{L}^{-1}\right)$ & $0.77 \pm 0.37(21)$ & $0.75 \pm 0.64$ & $0.76 \pm 0.53$ & & & & NS \\
\hline $\begin{array}{l}\text { Total Cholesterol } \\
\left(\mathrm{mMol} \mathrm{L}^{-1}\right)\end{array}$ & $2.92 \pm 0.39(21)$ & $2.82 \pm 0.53$ & $2.87 \pm 0.47(47)$ & & & & NS \\
\hline HDL $\left(\mathrm{mMol} \mathrm{L}^{-1}\right)$ & $1.32 \pm 0.43(21)$ & $1.69 \pm 0.69$ & $1.53 \pm 0.61(47)$ & 0.373 & $(0.026,0.720)$ & $0.63(55.9)$ & 0.036 \\
\hline $\operatorname{LDL}\left(\mathrm{mMol} \mathrm{L}^{-1}\right)$ & $1.33 \pm 0.45(20)$ & $0.96 \pm 0.62(23)$ & $1.13 \pm 0.57(43)$ & -0.363 & $(-0.703,-0.024)$ & $0.66(55.1)$ & 0.037 \\
\hline PAI-1 (ng mL $\left.{ }^{-1}\right)$ & $9.79 \pm 5.20(21)$ & $10.63 \pm 4.97(25)$ & $10.25 \pm 5.03$ & & & & NS \\
\hline IL-6 $\left(\mathrm{pg} \mathrm{ml}^{-1}\right)$ & $1.38 \pm 0.90(18)$ & $1.31 \pm 1.79(22)$ & $1.34 \pm 1.44(40)$ & & & & NS \\
\hline $\mathrm{CRP}\left(\mathrm{mg} \mathrm{L}^{-1}\right)$ & $2.57 \pm 2.68(20)$ & $1.05 \pm 0.93(24)$ & $1.74 \pm 2.05(44)$ & -1.515 & $(-2.693,-0.337)$ & $0.78(72.1)$ & 0.013 \\
\hline Adiponectin $\left(\mathrm{mg} \mathrm{L}^{-1}\right)$ & $8.66 \pm 8.26(21)$ & $12.66 \pm 10.08$ & $10.87 \pm 9.43(47)$ & & & & NS \\
\hline
\end{tabular}

Note: Where $\mathrm{n} \neq$ denoted number, actual sample number is presented in parenthesis. The difference between boys and girls were tested by independent t-tests. The 9\% Confidence Intervals (CI) and Effect Size Statistics (ES) were calculated for all statistically significant post-his findings. NS indicates not significant. Data are presented as a mean $\pm \bullet$ standard deviation, except for CRP where the median values were used

The boys had a greater body mass and was taller and performed more physical activity than girls (Table 1). The boys also had significantly greater $(\mathrm{p}<0.05)$ fasting levels of glucose, LDL and CRP and lower levels of HDL than girls (Table 2).

Percentages of youth who exceeded thresholds for CVD risk factors are summarized in Table 3. The majority of subjects $(75 \%)$ consumed a diet that exceeded recommended levels of total and saturated fat. Some girls presented with elevated levels of insulin more so than boys, although conversely, some boys presented with elevated levels of glucose more so than girls. A small number of individuals also presented with low levels of HDL (23\%), but in total there was a near equal distribution of boys and girls. Elevated CRP levels were evident in $46 \%$ of the cohort and demonstrated a bias toward boys. Numbers of individuals presenting multiple CVD risk factors are presented in Table 4 . About $88 \%$ of the sample had 2-6 CVD risk factors; $40 \%$ of boys and only $20 \%$ of girls presented 5 or more risk factors.

\section{DISCUSSION}

Although limited to relatively small numbers, these findings revealed a number of Scottish youth of South Asian ancestry with poor CVD profiles. The observations here are consistent with other research in the literature. South Asian youth tend to have elevated 75 
levels of HDL (Whincup et al., 2010), which was similarly evident in the current study. Boys had significantly higher levels of fasting blood glucose than girls (Table 2) with nearly $30 \%$ of boys presenting levels considered at risk (Table 3). Although no significant differences were noted between sexes for fasting insulin, nearly $30 \%$ of the girls had levels considered at risk (Table 3). In comparison to European Whites, South Asians also have a higher risk of type 2 diabetes during youth and in adulthood (Donin et al., 2010; Whincup et al., 2010). Since insulin resistance tends to precede hyperglycemia, the present findings appear to imply that adolescent girls of South Asian ancestry may be predisposed to Type 2 diabetes earlier than boys with its antecedents appearing and advancing in severity considerably prior to adulthood.

The most recent Scottish Health Survey reported that a large proportion of adolescents were currently meeting physical activity recommendations, approximately 60$84 \%$, although more boys achieved the recommendations more than girls (SG, 2009). Boys in the present study also reported higher physical activity levels than girls (Table 1). The PAQ-A (Kowalski et al., 1997) which measures general activity patterns was used. Direct comparison among studies using different measurement tools is problematic, especially with self-report measures. Nonetheless, South Asian adolescents of both sexes were not overly active, particularly girls, which was consistent with the literature concerning the physical activity levels of South Asians within the UK (Fischbacher et al., 2004). The majority of youth in the present study did not meet the physical activity recommendations. This is also evident in studies of younger children of South Asian ancestry (Owen et al., 2009).

Poor weight status also links to adverse cardiovascular profiles. Although the BMI and WC did not differ, on average, between boys and girls (Table 2), nearly $20 \%$ of the sample had a BMI and WC that placed them at risk (Table 3). Although these indirect indicators of adiposity may place youth at risk, other factors such as physical inactivity, low cardiorespiratory fitness, poor diet and genetic factors, may contribute to elevated insulin resistance observed in European South Asian compared to White youth (Whincup et al., 2010). Dietary habits recorded for this sample of Scottish South Asian youth are cause for concern as high dietary levels of total and saturated fat may influence increased insulin sensitivity, especially among South Asians in the UK (Singh et al., 1995). About $75 \%$ of the cohort (sex differences were negligible) reported diets high in both total and saturated fat (Table 3). This was generally consistent with recent observations which suggested that South Asian youth were more likely to have poorer dietary practices compared to their White UK peers; of interest, South Asian youth born in the UK were more likely to make or experience poor parental dietary choices (Harding et al., 2008). It appears, therefore, that the combination of physical inactivity, poor diet and poor weight status contributed to the increased risk of type 2 diabetes in this cohort of South Asian youth. Further clarification of the specific contributions of inactivity, diet and weight status is necessary to develop more effective strategies for early prevention of Type 2 diabetes in South Asians.

The significant difference in HDL levels between boys and girls was consistent with the literature for adolescents as HDL decreases, on average, in boys while remaining relatively stable in girls (Daniels and Greer, 2008).

Table 3: Percentage of youth with CVD risk classification based on currently used criterion thresholds

\begin{tabular}{|c|c|c|c|}
\hline Risk factor & Boys (\%) & Girls (\%) & Combined (\%) \\
\hline \multicolumn{4}{|l|}{ Weight status (BMI) } \\
\hline Obese & 9 & 0 & 4 \\
\hline Overweight & 23 & 15 & 19 \\
\hline Healthy weight & 60 & 70 & 65 \\
\hline Thin-grade 3 & 9 & 15 & 12 \\
\hline \multicolumn{4}{|l|}{ WC } \\
\hline At risk & 21 & 15 & 18 \\
\hline \multicolumn{4}{|l|}{ SBP and DBP } \\
\hline At risk & 18 & 12 & 15 \\
\hline Total fat (>30\%) & 77 & 73 & 75 \\
\hline Sat fat $(>10 \%)$ & 77 & 73 & 75 \\
\hline Insulin $\left(>15 \mu \mathrm{U} \mathrm{mL}^{-1}\right)$ & 4 & 27 & 20 \\
\hline Glucose $\left(\geq 5.6 \mathrm{mmol} \mathrm{L}^{-1}\right)$ & 29 & 4 & 15 \\
\hline $\begin{array}{l}\text { Triglycerides } \\
\left(\geq 1.7 \mathrm{mmol} \mathrm{L}^{-1}\right)\end{array}$ & 0 & 12 & 6 \\
\hline $\begin{array}{l}\text { Cholesterol } \\
\left(\geq 4.73 \mathrm{mmol} \mathrm{L}^{-1}(\mathrm{~B})\right) \\
\left(>3.34 \mathrm{mmol} \mathrm{L}^{-1}(\mathrm{G})\right)\end{array}$ & & & \\
\hline $\begin{array}{l}\text { Combined } \\
\text { HDL Cholesterol } \\
\left(\leq 1.05 \mathrm{mmol} \mathrm{L} \mathrm{L}^{-1}(\mathrm{~B})\right) \\
(\leq 1.29 \text { or }<1.03(\mathrm{G}))\end{array}$ & 0 & 0 & 0 \\
\hline $\begin{array}{l}\text { Combined } \\
\text { LDL Cholesterol } \\
\left(\geq 3.18 \mathrm{mmol} \mathrm{L}^{-1}(\mathrm{~B})\right) \\
\left(\geq 3.34 \mathrm{mmol} \mathrm{L}^{-1}(\mathrm{G})\right)\end{array}$ & 24 & 26 & 23 \\
\hline $\begin{array}{l}\text { All together } \\
\text { CRP }\end{array}$ & 0 & 0 & 0 \\
\hline$\left(\geq 1.0 \mathrm{mg} \mathrm{L}^{-1}\right)$ & 60 & 33 & 46 \\
\hline
\end{tabular}

Table 4: Number of individuals with multiple CVD risk factors

\begin{tabular}{lllrrrrrrr}
\hline participants & \multicolumn{1}{l}{ No. of risk factors } \\
\hline Girls & 0 & 1 & 2 & 3 & 4 & 5 & 6 & 7 & 8 \\
Boys & 0 & 1 & 11 & 4 & 3 & 2 & 2 & 0 & 1 \\
Total & 1 & 1 & 7 & 4 & 0 & 8 & 1 & 0 & 0 \\
\hline
\end{tabular}

Note: Of the 12 risk factors analyzed, no individual presented with more than 8 risk factors 
About $25 \%$ of the cohort presented HDL levels considered at risk (Table 3). This may be explained by the high dietary fat intake or perhaps insulin resistance (Donin et al., 2010). Boys and girls also differed significantly in LDL levels (Table 2), but no individuals presented levels of LDL or total cholesterol considered at risk (Table 3). This may reflect a trend noted among European adults of South Asian ancestry who tend to have lower levels of total cholesterol and LDL than White Europeans (Cappuccio et al., 1997).

Elevated levels of CRP are strongly associated with insulin resistance and risk of type 2 diabetes among adolescents (Balagopal et al., 2011; Tam et al., 2010). South Asian boys had significantly greater levels of CRP than girls (Table 2) and just less than one-half of the boys and girls had CRP levels considered at risk (Table 3). The elevated levels of CRP in this cohort were consistent with investigations involving South Asian youth (Whincup et al., 2010) and may have reflected elevated levels of insulin and glucose noted in part of the cohort. The long term consequences of elevated levels of CRP are still to be established, but some evidence suggests that CRP may represent an early biochemical indicator of future marker of atherosclerosis (Tam et al., 2010).

Elevated levels of PAI-1, IL-6 and low levels of adiponectin are independent predictors of type 2 diabetes in adolescence and CVD related events in adulthood (Balagopal et al., 2011; Tam et al., 2010). Data for the prevalence of these biomarkers in UK South Asian populations are limited and as such, it is difficult to evaluate our observations. Gender differences in the two risk factors were apparent (Table 2) so that the mean values of adiponectin presented by boys compared to girls may be cause for concern. Low levels of adiponectin in adults were predictive of CVDrelated events (Antoniades et al., 2009). It may be suggested that if low levels are present in childhood and adolescence, they may exacerbate the prevalence of CVD-related events later in adulthood. Although universally accepted 'at risk' thresholds for adiponectin are not available for adolescents, it has been hypothesised that adiponectin values between 8 and 9 $\mathrm{mg} \mathrm{L}^{-1}$ may be useful for identifying individuals at risk of poor CVD profiles (Gilardini et al., 2006). Further, in a relatively small sample of White youth 9-18 years $(\mathrm{N}=162)$, individuals with these levels of adiponectin had an 11-fold increase in the risk of developing metabolic syndrome (Gilardini et al., 2006). Given that the mean levels of adiponectin in this sample of Scottish South Asian boys fell within 8 and $9 \mathrm{mg} \mathrm{L}^{-1}$, it may be reasonable to suggest that some of the participants may be prone to type 2 diabetes as they enter adulthood.
As noted in Table 4, 88\% of this cohort of Scottish South Asian youth presented between 2 and 6 CVD risk factors and $40 \%$ of boys and $20 \%$ of girls presented 5 or more risk factors. The prevalence of CVD risk factors in this cohort was considerably greater compared to previous studies of White European youth which showed 2 risk factors in $16 \%$ of 261 participants (Ekelund et al., 2009) or clustering of risk factors in $11 \%$ of 1732 youth 9-15 years (Andersen et al., 2006). Given the small sample size, it is not certain whether the findings indicate an urgent need for intervention within Scottish South Asian populations. Nonetheless, the low subject number does not affect the significance of the results noted in Table 2 and we direct the reader to the moderate effect size and level of significance observed between genders for glucose, HDL, LDL and CRP.

Conflict of Interest: The researcher declares that they have no conflict of interest.

\section{CONCLUSION}

Although our findings are promising there are limitations to the study. The main limitation of the present study is the small sample size. Nonetheless, the low subject number does not affect the significance of results noted in Table 2 and we direct the reader to the moderate effect size and level of significance observed between genders for glucose, HDL, LDL and CRP. Further research is warranted with South Asian and other ethnic minority youth to confirm and advance the findings presented here. In addition, our findings indicate that there is a need for dietary and physical activity interventions within high risk adolescent ethnic groups.

\section{ACKNOWLEDGMENT}

The researcher wish to thank SEMSA for their advice and support. This study was financially supported by grants from the Chief Scientist Office for Scotland.

\section{REFERENCES}

Andersen, L.B., M. Harro, L.B. Sardinha, K. Froberg and U. Ekelund et al., 2006. Physical activity and clustered cardiovascular risk in children: A crosssectional study (The European youth heart study). Lancet, 368: 299-304. DOI: 10.1016/S01406736(06)69554-8

Andersen, L.B., N. Wedderkopp, H.S. Hansen, A.R. Cooper and K. Froberg, 2003. Biological cardiovascular risk factors cluster in Danish children and adolescents: The European youth heart study. Prev. Med., 37: 363-367. DOI: 10.1016/S0091-7435(03)00145-2 
Antoniades, C., A.S. Antonopoulos, D. Tousoulis and C. Stefanadis, 2009. Adiponectin: From obesity to cardiovascular disease. Obes. Rev., 10: 269-279. DOI: 10.1111/j.1467-789X.2009.00571.x

Balagopal, P.B., S.D.D. Ferranti, S. Cook, S.R. Daniels and S.S. Gidding et al., 2011. Nontraditional risk factors and biomarkers for cardiovascular disease: Mechanistic, research and clinical considerations for youth: A scientific statement from the American heart association. Circulation, 123: 2749-2769. DOI: 10.1161/CIR.0b013e31821c7c64

BHF, 2010. Coronary heart disease statistics. British Heart Foundation, London.

Buchan, D.S., S. Ollis, J.D. Young, N.E. Thomas and S.M. Cooper et al., 2011. The effects of time and intensity of exercise on novel and established markers of CVD in adolescent youth. Am. J. Hum. Biol., 23: 517-526. DOI: 10.1002/ajhb.21166

Cappuccio, F.P., D.G. Cook, R.W. Atkinson and P. Strazzullo, 1997. Prevalence, detection and management of cardiovascular risk factors in different ethnic groups in south London. Heart, 78: 555-563. PMID: 9470870

Cohen, J., 1988. Statistical Power Analysis for the Behavioral Sciences. 2nd Edn., Routledge, ISBN10: 0805802835, pp: 567.

Cole, T.J., K.M. Flegal, D. Nicholls and A.A. Jackson, 2007. Body mass index cut offs to define thinness in children and adolescents: International survey. BMJ, 335: 194-194. DOI: 10.1136/bmj.39238.399444.55

Daniels, S.R. and F.R. Greer, 2008. Lipid screening and cardiovascular health in childhood. Pediatrics, 122: 198-208. DOI: 10.1542/peds.2008-1349

DEFRA, 2004. Family Food-Report on the Expenditure and Food Survey.

Donin, A.S., C.M. Nightingale, C.G. Owen, A.R. Rudnicka and M.C. McNamara et al., 2010. Ethnic differences in blood lipids and dietary intake between UK children of black African, black Caribbean, South Asian and white European origin: The child heart and health study in England (CHASE). Am. J. Clin. Nutr., 92: 776-783. DOI: 10.3945/ajen.2010.29533

Ekelund, U., S. Anderssen, L.B. Andersen, C.J. Riddoch and L.B. Sardinha et al., 2009. Prevalence and correlates of the metabolic syndrome in a population-based sample of European youth. Am. J. Clin. Nutr., 89: 90-96. DOI: 10.3945/ajcn.2008.26649

Fischbacher, C.M., S. Hunt and L. Alexander, 2004. How physically active are South Asians in the United Kingdom? A literature review. J. Public. Health, 26: 250-258. DOI: 10.1093/pubmed/fdh158
Friedewald, W.T., R.I. Levy and D.S. Fredrickson, 1972. Estimation of the concentration of lowdensity lipoprotein cholesterol in plasma, without use of the preparative ultracentrifuge. Clin. Chem., 18: 499-502. PMID: 4337382

Gilardini, L., P.G. McTernan, A. Girola, N.F.D. Silva and L. Alberti et al., 2006. Adiponectin is a candidate marker of metabolic syndrome in obese children and adolescents. Atherosclerosis, 189: 401-407.

DOI: 10.1016/j.atherosclerosis.2005.12.021

Giskes, K., F.V. Lenthe, M. Avendano-Pabon and J. Brug, 2011. A systematic review of environmental factors and obesogenic dietary intakes among adults: Are we getting closer to understanding obesogenic environments? Obes. Rev., 12: e95e106. DOI: 10.1111/j.1467-789X.2010.00769.x

Harding, S., A. Teyhan, M.J. Maynard and J.K. Cruickshank, 2008. Ethnic differences in overweight and obesity in early adolescence in the MRC DASH study: The role of adolescent and parental lifestyle. Int. J. Epidemiol., 37: 162-172. DOI: $10.1093 /$ ije/dym252

Janz, K.F., E.M. Lutuchy, P. Wenthe and S.M. Levy, 2008. Measuring activity in children and adolescents using self-report: PAQ-C and PAQ-A. Med. Sci. Sports. Exerc., 40: 767-772. DOI: 10.1249/MSS.0b013e3181620ed1

Kowalski, K.C., P.R.E. Crocker and N.P. Kowalski, 1997. Convergent validity of the physical activity questionnaire for adolescents. Pediatr. Exerc. Sci., 9: 342-352.

Ledoux, M., J. Lambert, B.A. Reeder and J.P. Despres, 1997. A comparative analysis of weight to height and waist to hip circumference indices as indicators of the presence of cardiovascular disease risk factors. Canadian Heart Health Surveys Res. Group. CMAJ, 157: S32-38. PMID: 9220952

McCance, R.A. and E.M. Widdowson, 2002. McCance and Widdowson's The Composition of Foods. 6th Edn., Royal Society of Chemistry, ISBN-10: 0854044280, pp: 537.

Owen, C.G., C.M. Nightingale, A.R. Rudnicka, D.G. Cook and U. Ekelund et al., 2009. Ethnic and gender differences in physical activity levels among 9-10-year-old children of white European, South Asian and African-Caribbean origin: The Child Heart Health Study in England (CHASE Study). Int. J. Epidemiol., 38: 1082-1093. DOI: 10.1093/ije/dyp176 
Pearson, T.A., G.A. Mensah, R.W. Alexander, J.L. Anderson and R.O. Cannon et al., 2003. Markers of inflammation and cardiovascular disease: Application to clinical and public health practice: A statement for healthcare professionals from the centers for disease control and prevention and the American heart association. Circulation, 107: 499511. DOI: 10.1161/01.CIR.0000052939.59093.45

Pronk, N.P., 1993. Short term effects of exercise on plasma lipids and lipoproteins in humans. Sports Med., 16: 431-448.

SG, 2004. Analysis of ethnicity in the 2001 census: Summary report.

SG, 2009. The Scottish Health Survey.

Singh, R.B., S. Ghosh, A.M. Niaz, S. Gupta and I. Bishnoi et al., 1995. Epidemiologic study of diet and coronary risk factors in relation to central obesity and insulin levels in rural and urban populations of north India. Int. J. Cardiol., 47: 245255. PMID: 7721501

Steinberger, J., S.R. Daniels, R.H. Eckel, L. Hayman and R.H. Lustig et al., 2009. Progress and challenges in metabolic syndrome in children and adolescentsa scientific statement from the American heart associationatherosclerosis, hypertension and obesity in the young committee of thecouncil on cardiovascular disease in the young; council oncardiovascular nursing; and council on nutrition, physical activity and metabolism. Circulation, 119: 628-647. DOI: 10.1161/CIRCULATIONAHA.108.191394

Tam, C.S., K. Clement, L.A. Baur and J. Tordjman, 2010. Obesity and low-grade inflammation: A paediatric perspective. Obes. Rev., 11: 118-126. DOI: $10.1111 /$ j.1467-789X.2009.00674.X

Tamir, I., G. Heiss, C.J. Glueck, B. Christensen and P. Kwiterovich et al., 1981. Lipid and lipoprotein distributions in white children ages 6-19 yr. The lipid research clinics program prevalence study. J. Chronic Dis., 34: 27-39. DOI: 10.1016/00219681(81)90079-5
Tanner, J.M., 1962. Growth at Adolescence. 2nd Edn., Oxford, pp: 326.

Ten, S. and N. Maclaren, 2004. Insulin resistance syndrome in children. J. Clin. Endocrinol. Metab., 89: 2526-2539. DOI: 10.1210/jc.2004-0276

Whincup, P.H., C.M. Nightingale, C.G. Owen, A.R. Rudnicka and I. Gibb et al., 2010. Early emergence of ethnic differences in type 2 diabetes precursors in the UK: The Child Heart and Health Study in England (CHASE Study). PLoS Med., 7: e1000263-e1000263. DOI: 10.1371/journal.pmed.1000263

Whincup, P.H., J.A. Gilg, C.G. Owen and K. Odoki, K.G.M.M. Alberti et al., 2005. British South Asians aged 13-16 years have higher fasting glucose and insulin levels than Europeans. Diabet. Med., 22: 1275-1277. DOI: 10.1111/j.14645491.2005.01587.x

Whincup, P.H., J.A. Gilg, O. Papacosta, C. Seymour and G.J. Miller et al., 2002. Early evidence of ethnic differences in cardiovascular risk: Cross sectional comparison of British South Asian and white children. BMJ, 324: 635-635. DOI: $10.1136 / \mathrm{bmj} .324 .7338 .635$

WHO, 2003. Diet, nutrition and the prevention of chronic diseases: World Health Organ. Tech. Rep. Ser., 916: 1-149. PMID: 12768890

Yajnik, C.S., 2002. The lifecycle effects of nutrition and body size on adult adiposity, diabetes and cardiovascular disease. Obes. Rev., 3: 217-224. DOI: 10.1046/j.1467-789X.2002.00072.x

Zimmet, P., K.G. Alberti, F. Kaufman, N. Tajima and M. Silink et al., 2007. The metabolic syndrome in children and adolescents-an IDF consensus report. Pediatr. Diabetes., 8: 299-306. PMID: 17850473 